\title{
Strangulation of the small intestine caused by an intra-mesosigmoid hernia: a case report
}

\author{
Kotaro Hirashima ${ }^{1 *}$ (D), Kazutoshi Date ${ }^{1}$, Kanako Fujita ${ }^{1}$, Norihiko Koide ${ }^{1}$, Akihito Kamuro $^{2}$, Hiroshi Kato ${ }^{3}$ \\ and Nobuhiro Fujita ${ }^{1}$
}

\begin{abstract}
Sigmoid mesocolon hernia is an uncommon type of internal hernia with only a few cases reported to date. This disease entity can progress rapidly to cause vascular disturbance, necrosis, and perforation of the bowel wall; therefore, early diagnosis and surgical treatment are essential. We describe the case of an intra-mesosigmoid hernia in a 60-year-old man without history of previous abdominal surgery who presented with sudden acute abdominal pain and vomiting. Based on computed tomography, which showed ascites and small bowel obstruction, we diagnosed him as having strangulation of the small intestine caused by a sigmoid mesocolic hernia and performed emergency surgery. Laparotomy revealed small intestinal strangulation, extensive engorgement, and discoloration of bowel loops. Approximately $100 \mathrm{~cm}$ of the small intestine extending from the ligament of Treitz had undergone strangulation and herniated into the defect of sigmoid mesocolon, leading to a diagnosis of an intra-mesosigmoid hernia. Because the incarcerated portion of the small intestine was viable, we did not perform intestinal resection and reconstruction but closed the defect in the sigmoid mesocolon. His postoperative course was uneventful.
\end{abstract}

Keywords: Intra-mesosigmoid hernia, Strangulation, Internal hernia

\section{Background}

Internal hernia is a protrusion of the small intestine or other abdominal organs through peritoneal or mesenteric orifices within the peritoneal cavity, occasionally leading to strangulation or incarceration. Additionally, an internal hernia is a rare cause of small bowel obstruction in patients without a history of abdominal surgery or trauma with a reported incidence of up to $5.8 \%$ of small bowel obstruction [1-3]. However, if strangulated and left untreated, internal hernias demonstrate a mortality $>50 \%[4$, 5]. In cases presenting as an emergency, preoperative diagnosis is very difficult due to rarity of this entity and limited utility of imaging in cases of acute intestinal obstruction [6]. Sigmoid mesocolic hernia (SMH) is a rare type of congenital hernia, and intra-mesosigmoid hernia (IMSH) is the rarest among the SMHs [7-9]. We present a case of a rare type of primary internal hernia presenting with

\footnotetext{
* Correspondence: gxrrm911@outlook.com

${ }^{1}$ Department of Surgery, Joetsu General Hospital, 616 Daido-Fukuda, Joetsu

City, Niigata 943-8507, Japan

Full list of author information is available at the end of the article
}

strangulation of the small intestine secondary to an IMSH in a 60-year-old man.

\section{Case presentation}

A 60-year-old man with no history of similar episodes or any abdominal surgeries was admitted to our emergency department with sudden acute abdominal pain and vomiting. He showed no other symptoms except continuous vomiting and no flatus after onset. On general examination, pulse rate was $60 / \mathrm{min}$, and blood pressure was $107 / 75 \mathrm{~mm}$ of $\mathrm{Hg}$. He present abdominal distension, and bowel sounds decreased. Laboratory tests showed an elevated white blood cells (WBC) count $\left(21.7 \times 10^{3} /\right.$ $\mu \mathrm{l}$ ) although his C-reactive protein (CRP) level was within reference range (Table 1). Computed tomography (CT) of the abdomen revealed small bowel obstruction with poor contrast effect (Fig. 1), and there appeared to be radial compression of the blood vessels of the sigmoid colon. The other organs appeared normal. We diagnosed strangulation of the small intestine secondary to $\mathrm{SMH}$ and performed an emergency laparotomy. 
Table 1 Laboratory data on admission

\begin{tabular}{llll}
\hline WBC & $21.7 \times 10^{3} / \mu \mathrm{l}$ & $\mathrm{Na}$ & $138 \mathrm{mEq} / \mathrm{l}$ \\
RBC & $513 \times 10^{4} / \mu \mathrm{l}$ & $\mathrm{K}$ & $4.0 \mathrm{mEq} / \mathrm{l}$ \\
$\mathrm{Hb}$ & $15.8 \mathrm{~g} / \mathrm{dl}$ & $\mathrm{Cl}$ & $99 \mathrm{mEq} / \mathrm{l}$ \\
$\mathrm{Hct}$ & $46.8 \%$ & & \\
Plt & $16.3 \times 10^{4} / \mu \mathrm{l}$ & BUN & $19.9 \mathrm{mg} / \mathrm{dl}$ \\
& & $\mathrm{Cre}$ & $1.03 \mathrm{mg} / \mathrm{dl}$ \\
AST & $19 \mathrm{U} / \mathrm{l}$ & $\mathrm{CK}$ & $131 \mathrm{IU} / \mathrm{l}$ \\
ALT & $18 \mathrm{U} / \mathrm{l}$ & & \\
T-Bil & $0.6 \mathrm{mg} / \mathrm{dl}$ & PT & $92.0 \%$ \\
ALP & $131 \mathrm{U} / \mathrm{l}$ & PT-INR & 1.05 \\
Y-GTP & $34 \mathrm{U} / \mathrm{l}$ & APTT & $97.8 \%$ \\
TP & $8.2 \mathrm{~g} / \mathrm{dl}$ & & \\
Alb & $4.67 \mathrm{~g} / \mathrm{dl}$ & & \\
T-Cho & $218 \mathrm{mg} / \mathrm{dl}$ & & \\
LDH & $202 \mathrm{U} / \mathrm{l}$ & & \\
CRP & $0.32 \mathrm{mg} / \mathrm{dl}$ & &
\end{tabular}

Laparotomy revealed extensive engorgement of the small intestine and discoloration of bowel loops. Approximately $100 \mathrm{~cm}$ of the small intestine extending from the ligament of Treitz had been strangulated and showed herniation into the defect of sigmoid mesocolon (Richter-type hernia). The defect was incomplete and the right leaf of sigmoid mesocolon was remained, therefore, we diagnosed as an IMSH (Figs. 2 and 3). Because the incarcerated portion of the small intestine was viable, we did not perform intestinal resection and reconstruction, but we closed the defect in the sigmoid mesocolon. His postoperative course was uneventful, and he started to take a meal on the 3rd postoperative day and was discharged from our hospital on the 6th postoperative day.

\section{Discussion}

Internal hernia is caused by defects within the peritoneal cavity, which might be congenital, postoperative, and/or idiopathic. The incidence of internal hernias based on autopsy diagnosis is $0.2-2.0 \%$, and most of them are asymptomatic [1]. SMH (a type of internal hernia) is uncommon, accounting for approximately $5 \%$ of all internal hernias $[10,11]$.

Benson et al. have classified SMHs into three types [10]: (1) intersigmoid hernia (ISH): herniation into the intersigmoid fossa, situated at the attachment of the lateral aspect of the sigmoid mesocolon. This fossa is formed during fusion of the left peritoneal surface of the sigmoid mesentery with the parietal peritoneum of the posterior abdominal wall, the line of Toldt. (2) Transmesosigmoid hernia (TMSH): incarceration of intestinal loops through an isolated oval defect in the sigmoid mesocolon. No hernial sac is present. (3) Intramesosigmoid hernia (IMSH): a congenital, oval defect unrelated to the intersigmoid fossa is present in juxtaposition to the colon and involves only one leaf (lateral more common) of the sigmoid mesocolon with herniation. Normal fusion fascia is present, and the right leaf is intact in this setting. Our case is classified as an IMSH, which is the rarest type based on Benson's classification.

CT plays an important role in the evaluation of intestinal obstruction and acute abdomen [2]. It is a valuable tool for early diagnosis and planning for surgical treatment in patients with internal hernia. However, preoperative diagnosis of internal hernia using CT remains very difficult even after the present when it spread widely. Ours was a case of $\mathrm{SMH}$, for which in a majority of cases, diagnosis can be confirmed only during surgery $[12,13]$. However, a radiologist at our hospital could preoperatively confirm diagnosis of $\mathrm{SMH}$ in our case. Our patient related no history of abdominal surgeries or trauma. However, patients presenting with small bowel obstruction and a positive history of tuberculosis or previous surgeries should be evaluated for the possibility of an internal herniation causing the obstruction.

Patients with small bowel obstruction refractory to conservative therapy require emergency surgical treatment if an internal herniation is suspected, and laparoscopy is

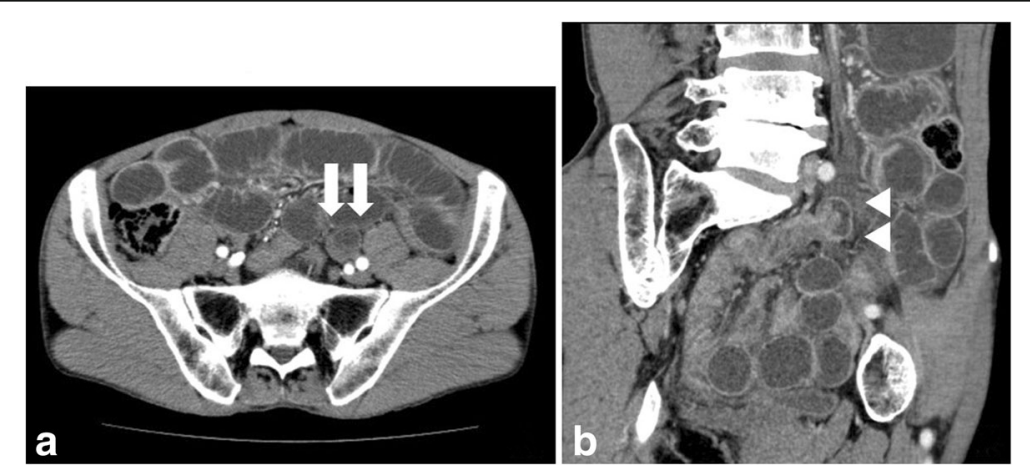

Fig. 1 Abdominal computed tomography (CT) scan showing small bowel obstruction. a Axial section (white arrows). b Coronal section (white arrowheads) 


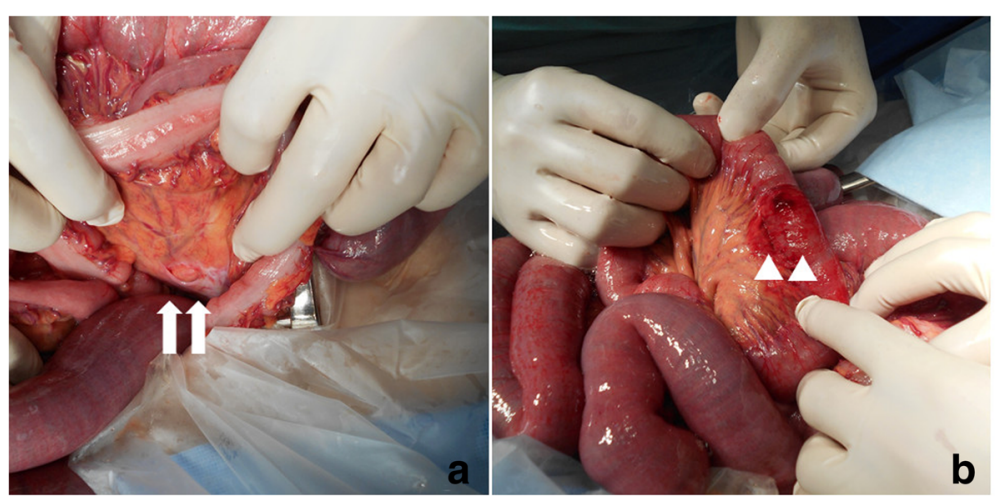

Fig. 2 a Laparotomy showing a sigmoid mesocolon defect (white arrows). b Approximately $100 \mathrm{~cm}$ of the small intestine extending from the ligament of Treitz is seen to have herniated into the defect of sigmoid mesocolon (Richter-type hernia), although the incarcerated portion of the small intestine is observed to be viable (white arrowheads)

useful if there is no evidence of strangulation or necrosis. Recently, some reports have recommended laparoscopic abdominal surgery for both diagnosis and surgical treatment $[11,14,15]$. Cases presenting with an ISH and IMSH do not show a complete defect in the mesosigmoid; therefore, laparoscopic detachment of peritoneal adhesions to enable sigmoid colon mobilization is often possible and sufficient. Moreover, the defect can be sutured laparoscopically. In our case, we performed an open

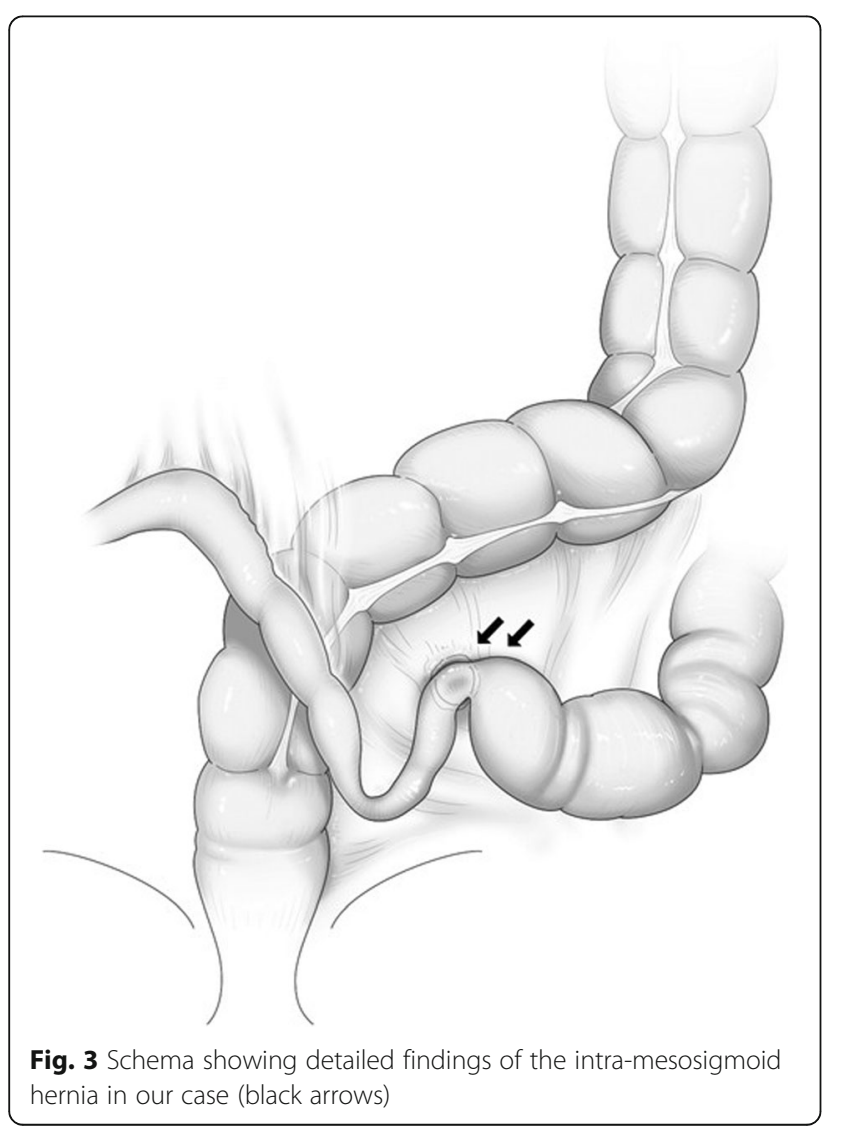

laparotomy because the small intestine was filled with intestinal fluids and grossly engorged due to intestinal obstruction.

\section{Conclusions}

We describe a case of an IMSH, which is a rare type of $\mathrm{SMH}$. Although rare and often underdiagnosed, internal hernias are an important cause of intestinal obstruction given the high mortality associated with this disease entity. Primary internal hernias should be considered among the differential diagnosis in adults with no previous history of surgery or trauma who present with acute intestinal obstruction. If clinicians identify an internal hernia, it may be better to take SMH into consideration as a likely diagnosis, which ought to be immediately confirmed followed by emergency surgical treatment.

\section{Abbreviations}

CRP: C-reactive protein; CT: Computed tomography; IMSH: Intra-mesosigmoid hernia; ISH: Intersigmoid hernia; SMH: Sigmoid mesocolic hernia;

TMSH: Trans-mesosigmoid hernia; WBC: White blood cells

\section{Acknowledgements}

We thank Mr. Yoshihiko Tsuda, who is a medical designer, for designing the schema of an intra-mesosigmoid hernia for the manuscript.

\section{Authors' contributions}

$\mathrm{KH}$ and $\mathrm{KD}$ are the surgeons who operated on the patient. AK and HK analyzed and interpreted the results of imaging. The manuscript was drafted by KF and NK. NF supervised the preparation of this case report. All authors have read and approved the final manuscript.

Ethics approval and consent to participate

Not applicable.

\section{Consent for publication}

Written informed consent was obtained from the patient for publication of this case report and any accompanying images. A copy of the written consent is available for review by the Editor in Chief of this journal.

\section{Competing interests}

The authors declare that they have no competing interests. 


\section{Publisher's Note}

Springer Nature remains neutral with regard to jurisdictional claims in published maps and institutional affiliations.

\section{Author details}

'Department of Surgery, Joetsu General Hospital, 616 Daido-Fukuda, Joetsu City, Niigata 943-8507, Japan. ${ }^{2}$ Department of Gastroenterology, Joetsu General Hospital, 616 Daido-Fukuda, Joetsu City, Niigata 943-8507, Japan. ${ }^{3}$ Department of Radiology, Joetsu General Hospital, 616 Daido-Fukuda, Joetsu City, Niigata 943-8507, Japan.

Received: 18 August 2017 Accepted: 7 December 2017

Published online: 21 December 2017

\section{References}

1. Zissin R, Hertz M, Gayer G, Paran H, Osadchy A. Congenital internal hernia as a cause of small bowel obstruction: CT findings in 11 adult patients. $\mathrm{Br} \mathrm{J}$ Radiol. 2005;78:796-802.

2. Kar S, Mohapatra $V$, Rath PK. A rare type of primary internal hernia causing small intestinal obstruction. Case Rep Surg. 2016;2016:3540794. doi:10.1155/ 2016/3540794. Epub 2016 Nov 23.

3. Newsom BD, Kukora JS. Congenital and acquired internal hernias: unusual causes of small bowel obstruction. Am J Surg. 1986;152:279-85.

4. Harrison OJ, Sharma RD, Niayesh MH. Early intervention in intersigmoid hernia may prevent bowel resection--a case report. Int J Surg Case Rep. 2011:2:282-4.

5. Martin LC, Merkle EM, Thompson WM. Review of internal hernias: radiographic and clinical findings. AJR Am J Roentgenol. 2006;186:703-17.

6. Ghiassi S, Nguyen SQ, Divino CM, Byrn JC, Schlager A. Internal hernias: clinical findings, management, and outcomes in 49 nonbariatric cases. J Gastrointest Surg. 2007;11:291-5.

7. Yang C, Kim D. Small bowel obstruction caused by sigmoid mesocolic hernia. J Surg Case Rep. 2014;2014(5):rju036. Published online 2014 Feb 5. doi:10.1093/jscr/rju036

8. Puri V, Bertellotti RP, Garg N, Fitzgibbons RJ Jr. Intramesosigmoid hernia: a rare type of congenital internal hernia. Hernia. 2007;11:463-5.

9. Hansmann GH, Morton SA. Intraabdominal hernia. Arch Surg. 1939:39:973-7.

10. Benson JR, Killen DA. Internal hernias involving the sigmoid mesocolon. Ann Surg. 1964:159:382-4.

11. Van der Mieren G, de Gheldere C, Vanclooster P. Transmesosigmoid hernia: report of a case and review of the literature. Acta Chir Belg. 2005;105:653-5.

12. Kuga T, Taniguchi S, Inoue T, Zempo N, Esato K. The occurrence of a strangulated ileus due to a traumatic transmesenteric hernia: report of a case. Surg Today. 2000;30:548-50.

13. Yip AW, Tong KK, Choi TK. Mesenteric hernias through defects of the mesosigmoid. Aust N Z J Surg. 1990;60:396-9.

14. Nihon-Yanagi $Y$, Ooshiro M, Osamura A, Takagi R, Moriyama A, Urita T, Yoshida $Y$, Tanaka H, Sugishita Y, Oshiro T, et al. Intersigmoid hernia: report of a case. Surg Today. 2010;40:171-5.

15. Kan H, Suzuki H, Takasaki H, Sasaki J, Furukawa K, Tajiri T. A case of an intramesosigmoid hernia. J Nippon Med Sch. 2009;76:13-8.

\section{Submit your manuscript to a SpringerOpen ${ }^{\circ}$ journal and benefit from:}

- Convenient online submission

- Rigorous peer review

- Open access: articles freely available online

- High visibility within the field

- Retaining the copyright to your article 